\title{
OKOLJSKI VIDIKI OHRANJANJA IN ZAŠČITE VRTAČ V SLOVENIJI
}

\author{
Mateja Breg \\ Geografski inštitut Antona Melika ZRC SAZU \\ Gosposka 13, 1000 Ljubljana, Slovenija \\ e-mail: mateja.breg@zrc-sazu.si
}

Izvirni znanstveni članek

COBISS 1.01

\section{Izvleček}

Vrtača, unikatna kraška oblika in rezultat dolgotrajnih krasotvornih procesov, v Sloveniji ni posebej zaščitena $\mathrm{v}$ nobenem pravnem dokumentu. $\mathrm{Na}$ izbranih primerih so predstavljene značilnosti tradicionalne in sodobne rabe vrtač, primeri trajne degradacije ter vidnejši negativni in pozitivni okoljski učinki. Predstavljeni so obstoječi načini zaščite in možnosti za trajno ohranitev vrtač pri načrtovanju rabe prostora.

Ključne besede: vrtača, reliefna oblika, zaščita, degradacija, kras, Slovenija.

\section{ENVIRONMENTAL ASPECTS OF DOLINES PROTECTION IN SLOVENIA}

\begin{abstract}
The doline is a unique karst landform and a result of long-term karst-shaping processes, which is not specially protected in any legal documents. The represented examples show some characteristics of traditional and modern usage of dolines, examples of permanent degradation and more significant negative and positive environmental impacts. Current ways of protecting and possibilities for a permanent preservation of dolines in the planning of spatial usage are also shown.
\end{abstract}

Key words: doline, landform, protection, degradation, karst, Slovenia. 


\section{UVOD}

Vrtača je kraška reliefna oblika, kjer potekajo specifični fizičnogeografski procesi, ob katerih se razvije značilno življenjsko okolje. Ugodne naravne razmere v vrtači omogočajo prisotnost različnih antropogenih dejavnosti. Z izbranimi primeri rabe vrtač bomo predstavili vlogo vrtač, negativne in pozitivne okoljske učinke, ki so posledica tradicionalne in dokaj sonaravne rabe vrtač. Ker pa raba vrtač postaja vedno bolj nesonaravna, so vrtače v nekaterih pokrajinah še posebej ogrožene. Poleg okoljskega obremenjevanja je treba izpostaviti spreminjanje naravnega reliefa $\mathrm{z}$ zasipavanjem in pozidavo vrtač. Razvijajoča se urbana naselja in avtoceste se nenadzorovano širijo preko pomembnih območij vrtač (Logatec, Kras itd.). Največjo degradacijo pa povzročajo nastajajoče storitveno industrijske cone, ki s sklenjenimi pozidanimi površinami pokrijejo večje površine vrtač.

Povod za prispevek o zaščiti vrtač izvira iz raziskovanja dolgotrajne degradacije vrtač na Logaškem polju (Breg 2007a) in dejstva, da v strokovni in laični javnosti ne namenjamo zadostne pozornosti njihovemu ohranjanju in zaščiti. Za razliko od podzemnih jam, s katerimi upravlja Zakon o varstvu podzemnih jam (Ur.l. RS, št. 2/2004), za ravnanje z vrtačami ne obstaja poseben zakonski predpis. Tako kot je kraška jama posebnost kraškega podzemlja, je vrtača posebnost kraškega površja, a je kot človeku dostopnejši objekt še bolj izpostavljena. V Sloveniji trenutno posvečamo pozornost samo zaščiti izjemnih vrtač, ki so ovrednotene bodisi kot naravna ali kulturna vrednota, lahko pa tudi širše v okviru zavarovanega območja (naravni park, naravni rezervat itd.). $\mathrm{Z}$ ozirom na razlike $\mathrm{v}$ tradicionalnih in intenzivnih načinih rabe vrtač, je treba najti ustrezen način $v$ načrtovanju rabe prostora na območjih vrtač in določiti možnosti za njihovo ohranjanje.

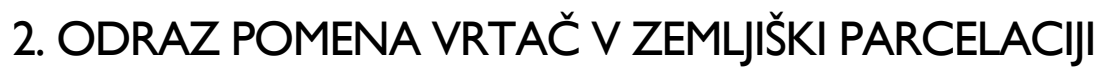

Od agrarne, do industrijske in postindustrijske dobe so se z napredkom v znanju in tehnologiji posegi v kraško površje stopnjevali. Uporaba $\mathrm{v}$ človeške namene je naravno vrtačo spremenila v kulturni objekt, del kultivirane pokrajine. Stoletja je vrtača predstavljala priložnost za agrarne dejavnosti (vrtovi, njive, travniki, pašniki) in vodooskrbo (kali, lokve). V naravi vidni in ohranjeni ostanki tradicionalne rabe vrtač, ki jih še lahko srečamo v kraških pokrajinah po Sloveniji, so predvsem kmetijsko obdelane vrtače, suhi zidovi, lokve in kali.

Nekdaj pomembno kmetijsko vlogo vrtač lahko določimo iz parcelacije kraškega površja v preteklosti. V ta namen smo interpretirali Franciscejski kataster (1823) za območje Logaškega polja (Slika 1). Kmetijsko pomembnejše vrtače z njivami, vrtovi in travniki so na katastru posredno razpoznavne, saj so označene kot bolj ali manj sferično oblikovane parcele. Vrtače v katerih so bili leta 1823 pašniki ali gozd na katastru niso določljive, ker niso označene kot samostojna parcela, kar kaže na njihovo manjšo gospodarsko vlogo. Lokacije in obliko teh vrtač smo dopolnili z analizo letalskega posnetka iz leta 1944. Dejstvo, da je zemljiška razdelitev posamezne katastrske občine odraz reliefnih značilnosti, v tem primeru značilne oblike vrtače, kaže na veliko družbeno-ekonomsko vlogo vrtač v preteklosti. 
Slika 1: Raba tal v vrtačah leta 1823 (Franciscejski kataster katastrske občine Dolenji Logatec). Figure 1: The land use of dolines in year 1823 (Franciscan cadastral map of cadastral municipality Dolenji Logatec).

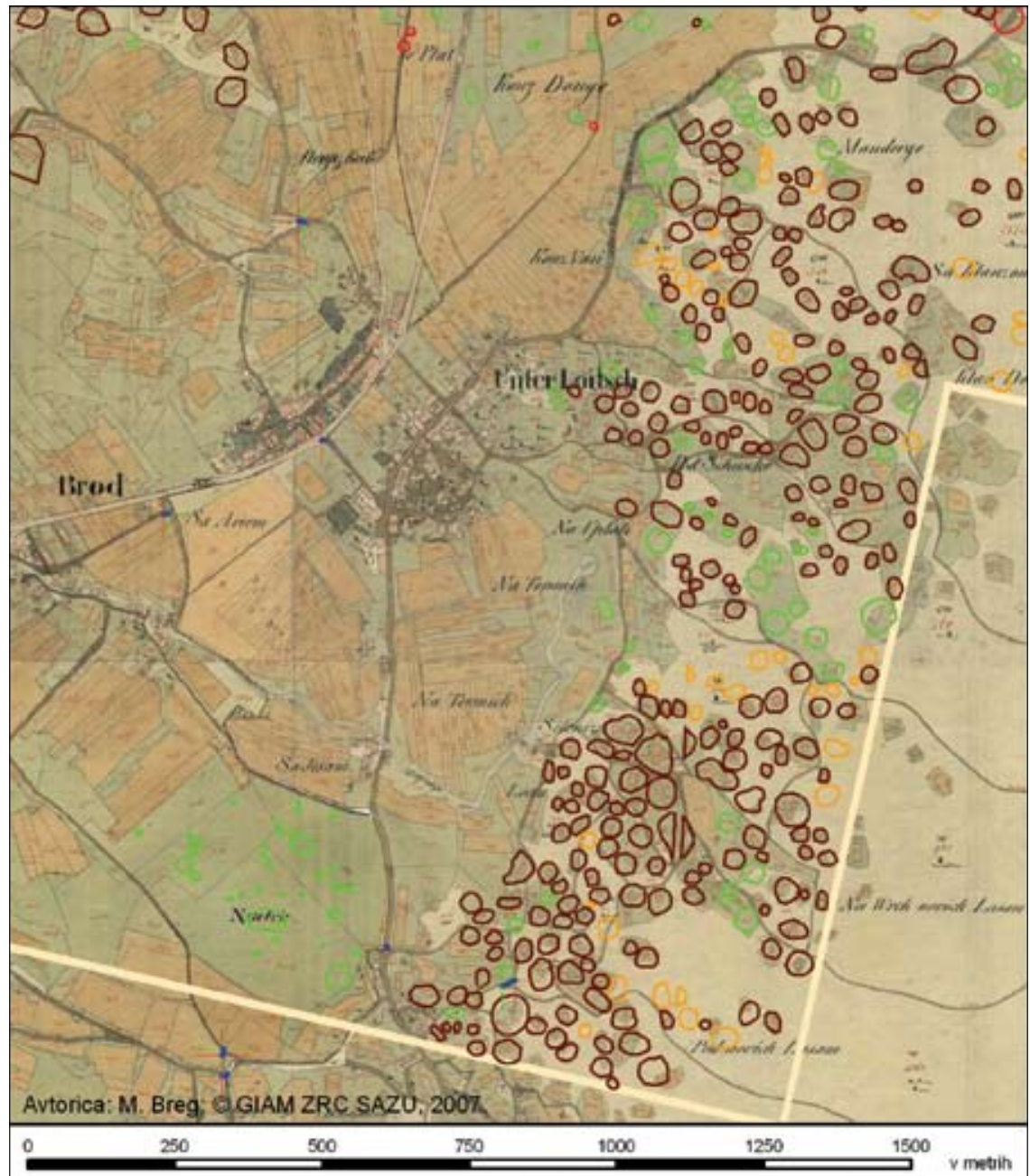

Raba tal na območju vrtač na Franciscejskem katastru leta 1823

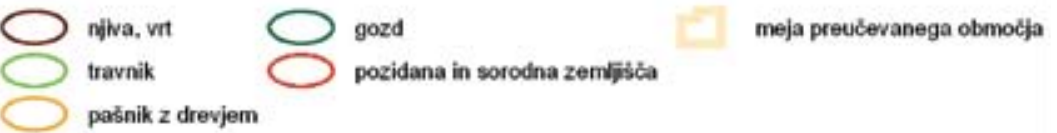

Vir: DOF5, 2005, $\odot$ GURS: Franciscejski kataster, 1823, @ Arhiv RS. 
Posledice nekdanje kmetijske vloge vrtač so ohranjene do danes in razvidne tudi iz parcelacije veljavnega zemljiškega katastra (GURS 2007). Kot primer predstavljamo parcelacijo katastrske občine Hrpelje (Slika 2). S samim pregledom katastra dobimo podatke o lokaciji, približni obliki, velikosti in predvsem agrarni vlogi vrtače, katere lahko dopolnimo ali preverimo z vizualno fotointerpretacijo letalskih posnetkov ali s terenskim raziskovanjem. Posamezne vrtače so razdeljene $\mathrm{v}$ manjše parcele, $\mathrm{v}$ obliki koncentričnih krogov ali zemljiških prog, skladno z obliko in velikostjo vrtače. Na območju med vrtačami so parcele večje. To območje je pripadalo celotni vaški skupnosti te katastrske občine in je bilo namenjeno predvsem pašnikom. Do nekaterih vrtač so vrisane tudi dostopne poti. Večina označenih vrtač je bilo preoblikovanih, s tem ko so v njih dovažali okoliško zemljo ter obdelovali njive in vrtove. Rezultate analize parcelacije na katastru smo preverili z letalskim posnetkom istega območja in ugotovili, da območja bolj ali manj okroglih parcel popolnoma sovpadajo $\mathrm{z}$ ohranjenimi vrtačami. Tudi suhi zidovi znotraj vrtač se ujemajo $\mathrm{z}$ mejami parcel. Nekatere vrtače so se »ohranile« v parcelaciji, medtem ko jih v naravi ne moremo več razpoznati. Še nekaj desetletij nazaj je bila skoraj vsaka vrtača obdelana. Danes so opuščene, zarašča jih grmovje in gozd, nekatere pa so že zasute.

Slika 2: Prisotnost vrtač na veljavnem katastrskem načrtu (katastrska občina Hrpelje).

Figure 2: The presence of dolines on current cadastral map (cadastral municipality Hrpelje).

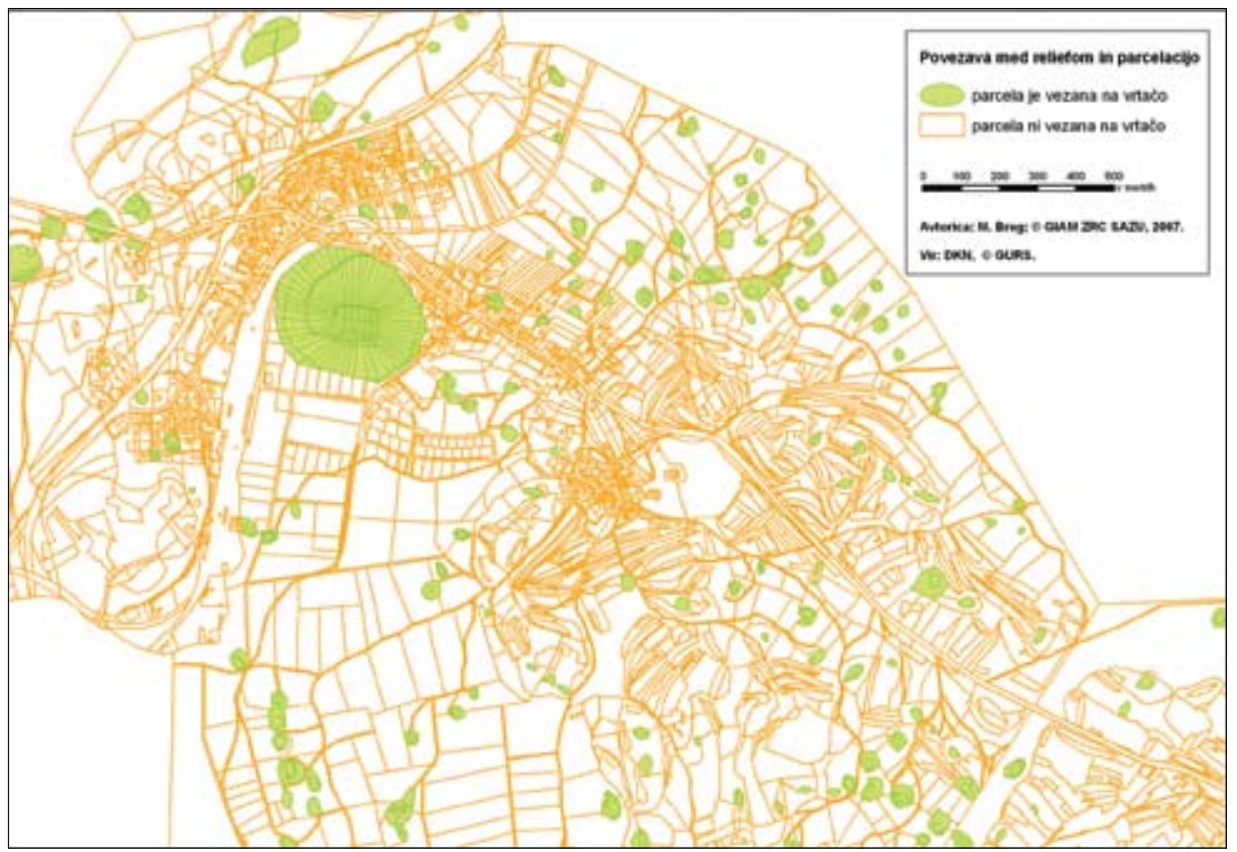




\section{TRADICIONALNA RABA VRTAČ IN OKOLJSKI UČINKI}

»Na Krasu so bila v preteklosti vsa zemljišča, kjer je bilo vsaj malo prsti, prilagojena za agrarno rabo. Danes je veliko kmetijskih zemljišč opuščenih, o nekdanji rabi pa pričajo ohranjeni sledovi čiščenja kamenja. Čiščenje površja je pomenilo pobiranje, odbijanje in izkopavanje skal, ki so štrlele na površje. Kamenje so zložili v suhe zidove ali groblje (Mihevc 2005).« Tudi stoletna tradicionalna raba vrtač je povzročila različne okoljske učinke v pokrajinskih sestavinah, le da so ti učinki bolj ali manj sonaravni. Sovpadajo predvsem z pripravo in oblikovanjem kmetijskega zemljišča v vrtači in načinom kmetovanja.

Mihevc (2005) je sledove stoletne agrarne rabe, ki se odražajo v morfologiji površja, dokazoval s količino kamenja, ki je bila preložena za pridobitev obdelovalnih površin. Intenzivno poseganje v površinsko morfologijo je vplivalo na erozijo prsti pri nekaterih vrtačah. Intenzivnost posegov $\mathrm{v}$ prostor nam pokaže količina $\mathrm{v}$ groblje in suhe zidove zloženega kamenja. Tako je bilo na območju katastrske občine Volčji Grad očiščenega 9812 $\mathrm{m}^{3} / \mathrm{km}^{2}$ kamenja, v Divači $2825 \mathrm{~m}^{3} / \mathrm{km}^{2}$ in najmanj, $488 \mathrm{~m}^{3} / \mathrm{km}^{2}$, pri Račicah. Površine na tankoplastovitih apnencih ali apnencih $\mathrm{z}$ roženci, ki razpadajo v manjše kamne, grušč ali pesek, so bile bolj očiščene zato je na njih nastalo več njiv, travnikov in pašnikov. Na kompaktnih čistih apnencih je kamnitost večja, sledov posegov pa manj (Mihevc 2005).

Gradnja suhih zidov pa ima lahko tudi pozitivne okoljske učinke. Poleg tega, da so suhi zidovi edinstven kulturni element kraške pokrajine v njih pa se oblikuje tudi značilno življenjsko okolje. Medtem ko vzdrževani suhi zidovi stoletja ostajajo nespremenjeni, zaraščeni zaradi listnega opada in nastajajočega humusa, prekritega z mahovi, počasi tonejo $\mathrm{v}$ objemu tal. Večina suhih zidov je poraščena z grmovjem, tako da so od daleč videti kot žive meje, kar v takšnem stanju tudi so. V suhih zidovih živijo kuščarji in kače, s čimer je povedano največ o naravni vrednosti tega življenjskega prostora. Od kuščaric sta značilni kraška (Podarcis melisellensis) in črnopikasta (Algyroides nigropuntatus), od kač črnica (Coluber viridiflavus) in modras (Vipera ammodytes). Na zidovih poraščenih z lišaji, se dobro počutijo tudi nočni metulji iz družine sovk (Noctuidae) (Geister 1999).

Del tradicionalne rabe vrtač so tudi kraški kali namenjeni vodooskrbi. Najpreprostejši kali so imeli v tla skopane kotanje, za silo urejeni so bili obzidani s suhim zidom vsaj po eni strani, bolje urejeni z več strani, a vsi so imeli naravno dno in bregove. Poznamo pa tudi izumetničene kale, $z$ betonskim dnom in brežino in še $z$ betonsko ograjo povrhu. V stoječi vodi in na brežini kalov uspevajo različne rastlinske in živalske vrste. Kot že ime samo pove, živi v kalih kalnica (Eristalis tenay), ki je bolj gnojnična kakor kalna muha. Kalno dno je včasih videti rdeče, obarvajo ga navadni tubifeksi (Tubifex tubifeks), deževnikom sorodni črvi, ki z zamahi zadka povzročajo kroženje kisika v zadušljivi vodi. Kal je pomembno mrestišče, zlasti žab, ki ne živijo v vodi; takšni sta tudi navadna krastača (Bufo bufo) in zelena rega (Hyla arborea). Devet desetin kalov je danes, ko ni več potrebe po skupnih vaških napajališčih za živino, zasutih, nekaj je zaraščenih, usoda preostalih pa je negotova, saj niso vsi zavarovani (Geister 1999). 


\section{OKOLJSKI UČINKI ZASIPAVANJA IN POZIDAVE VRTAČ}

Pomen vrtač je vsekakor začel upadati z zmanjševanjem pomena kmetijskih dejavnosti. $Z$ tehnološkim razvojem in mehanizacijo kmetijske proizvodnje se je njihova družbena vloga zelo zmanjšala. Najprej so postale fizična ovira za strojno poljedelstvo, s širjenjem proizvodnih in storitvenih dejavnosti pa tudi ovira za gradnjo cest, železnic; naselij ter industrijskih con. V procesu spreminjanja njihove družbene vloge pa so vrtače na poti do končnega izginotja postale tudi odlagališča odpadkov. Kljub uporabnosti vrtač se na krasu že od nekdaj kaže težnja po njihovem zasutju. Človek nasipava v komunalni, gradbeni, prometni, industrijski in kmetijski dejavnosti. Pri zasipavanju se uporablja različno odpadno gradivo, ki se razlikuje glede na obdobje zasipavanja.

Že za potrebe kmetijske rabe so vrtače zasipavali in povsem izravnavali z okoliškim površjem. Predvsem travniške vrtače so bile izpostavljene v obdobju pojava strojne mehanizacije. S časovnim presekom skozi leta 1823, 1944 in 2005 smo na Logaškem polju ugotavljali spremembe v rabi tal v vrtačah (Breg 2007b). Z historično-geografsko analizo Franciscejskega katastra (1823), starih letalskih posnetkov (1944) in digitalnega ortofoto načrta (2005) smo na $6 \mathrm{~km}^{2}$ preučevanega območja določili 868 vrtač (Slika 3). Alarmanten je podatek, da se je do leta 2005 povsem ohranilo samo $11 \%$ vrtač. Istega leta so travniki uspevali na lokacijah 299 vrtač, vendar je samo 10 vrtač v celoti ohranjenih, medtem ko so vse preostale izravnane $\mathrm{z}$ okoliškimi travniki in nerazpoznavne. Njive in vrtovi so $\mathrm{v}$ letu 2005 uspevali na lokacijah 75 vrtač, od tega 53 nerazpoznavnih in 22 ohranjenih vrtač. Gozd je poraščal 32 ohranjenih vrtač in 108 lokacij danes nerazpoznavnih vrtač. Število z gozdom poraščenih lokacij vrtač je v skladu s trendom zaraščanja travniških in pašniških površin do leta 2005 izjemno poraslo. Najbolj zaskrbljujoč za ohranitev vrtač pa je nedvomno porast pozidanih in sorodnih površin, ki so za vedno uničile $37 \%$ vrtač s tem ko so prekrile 317 od skupno 868 vrtač. 294 vrtač je v celoti pozidanih in za vedno izgubljenih, 23 pa je delno ohranjenih, ker so le delno pozidane s stavbami ali pa jih cesta oziroma železnica samo delno prečita. Velik del pozidanih površin je posledica izgradnje proizvodnih in storitvenih dejavnosti, ki se ob železnici širijo proti severovzhodu (Breg 2007b). Primer Logatca nazorno dokazuje upadanje vrtač in dejstvo, da so vrtače $z$ vidika načrtovalcev rabe prostora že od nekdaj povsem neupoštevane.

Z naraščanjem števila prebivalcev, širjenjem urbanih površin in proizvodnih dejavnosti se povečujejo pozidane površine in količine odpadkov. Glede na predhodne študije (Smrekar et al. 2005) je na aktivnih divjih odlagališčih ugotovljen prevladujoč delež gradbenih odpadkov (70 \%), medtem ko se delež komunalnih in nevarnih zmanjšuje zaradi urejenega odvoza. $\mathrm{Ob}$ upoštevanju tega podatka, obstaja nevarnost, da se bo v prihodnje nadaljevalo zasipavanje vrtač z odpadnim gradbenim materialom, ki bo nastajal vzporedno s priseljevanjem prebivalcev ter interesom po novih in obnovljenih stanovanjih $\mathrm{v}$ intenzivno razvijajočih se naseljih na krasu kot so Logatec, Sežana, Divača, Kozina itd.

V nekaj desetletjih so postala odlagališča odpadkov v vrtačah nespregledljiv antropogen element pokrajine. V naravi odložen odpadni material (gradbeni, industrijski, komunalni,...) predstavlja najbolj neodgovoren ter neetičen poseg v okolje in s tem v kraške oblike, ki so v določeni fazi izpostavljene tudi degradaciji. Odlagališča v vrtačah je podrobneje opisal 
Slika 3: Upadanje števila vrtač na Logaškem polju v obdobju 1823 - 2005.

Figure 3: Decrease in the number of dolines on Logaško polje in the period 1823 - 2005.

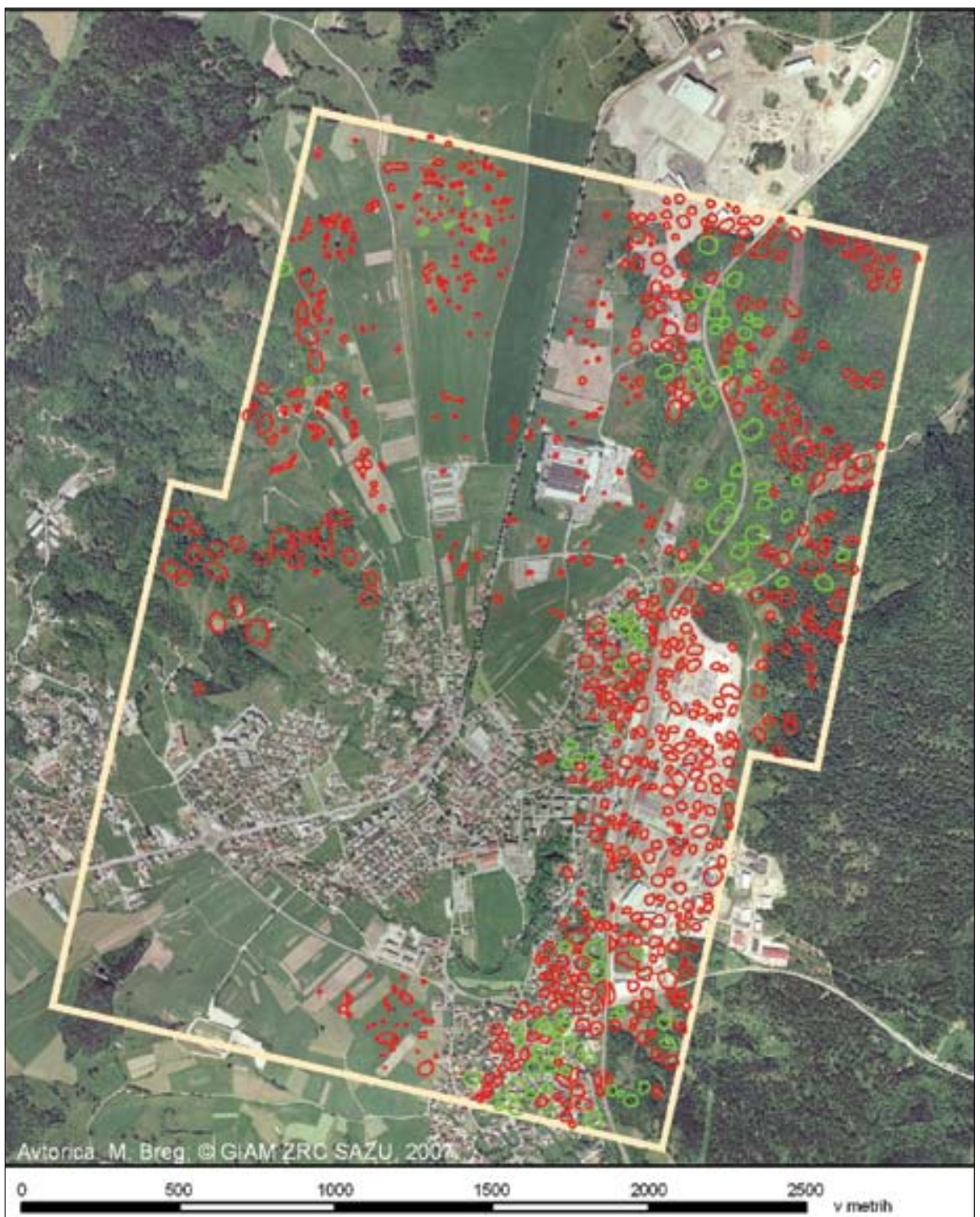

\section{Stanje ohranjenosti vrtač v letu 2005}

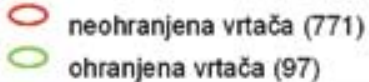


Šebenik (1994), v okviru svoje raziskave o neurejenih odlagališčih v Sloveniji. Na vzorčnih območjih občine Kamnik in naselja Podroteja je ugotavljal in določal glavne značilnosti neurejenih odlagališč odpadkov in njihove pokrajinskoekološke učinke, tudi v kraški pokrajini. Dve tretjini vrtač z odpadki je v gozdu ali pa so poraščene z grmovjem. Slabih 15 \% zasmetenih vrtač pa je travnikov ali še nezaraščenih, zapuščenih pašnikov. Za ilegalno odlaganje odpadkov so "primerne« lokacije, ki imajo določene lastnosti primerne za dovoz odpadkov: dostopnost, prikritost (depresijske oblike), zaraščenost, odmaknjenost, nefunkcionalnost, zapuščenost območja.

Kakšni bodo kratko- in dolgoročni okoljski učinki razpadanja odpadkov, je odvisno od fizičnogeografskih značilnosti vrtače in od tipa zasipnega materiala. V konkavni vrtači se razgradni produkti (plini) zadržujejo dalj časa in vplivajo na intenzivnost korozije. Deževnica prenika skozi plasti odloženih odpadkov, jih razkraja in odnaša razgradne produkte v kraške razpoke in naprej v vodonosnik. Najpomembnejša kemijska reakcija poteka med različnimi apnenci ali dolomiti $\left(\mathrm{CaCO}_{3}\right)$, vodo $\left(\mathrm{H}_{2} \mathrm{O}\right)$ in plinom ogljikovim dioksidom $\left(\mathrm{CO}_{2}\right)$. Odlagališča odpadkov so vir onesnaženih izcednih voda, plinov in trdnih odpadkov, ki vplivajo na to reakcijo in na hitrost raztapljanja apnenca. Pri anaerobnem razkroju biološko razgradljivih odpadkov se ob prisotnosti mikroorganizmov tvori bioplin. $\mathrm{CO}_{2} \mathrm{v}$ prsti pa povečuje stopnjo korozije na apnenčasto kamninsko podlago. Čeprav je dno v vrtačah ponavadi zapolnjeno $\mathrm{z}$ različnimi ilovkami, ki zmanjšujejo ali celo preprečujejo večje izpiranje v podzemlje, se zaradi povečane korozivnosti prenikajoče vode, ki vsebuje bioplin (ogljikov dioksid in metan), posamezne odtočne razpoke povečajo in pospešijo odtok kontaminirane vode. Hkrati pa se nekatere nevarne snovi nevtralizirajo v prsti pod odpadki. Večjo nevarnost za vodonosnik lahko predstavljajo območja, kjer tega filtra ni. Največjo nevarnost za vodni vir predstavljajo odlagališča na ožjih varstvenih območjih vodarn.

V večjih količinah v naravi odložene smeti pa oblikujejo tudi nov življenjski prostor rastlin in živali. Na smetišču pogosto naletimo na »floristični Babilon«, saj so poleg smeti prinesena tudi semena in druge oblike gojenih rastlin in lončnic. Ob potepuških psih, mačkah in podganah je med obiskovalci smetišč več vrst okoliških ptic, ki tam tudi gnezdijo. Takšna prvotno odprta odlagališča v vrtačah so pogosto »sanirali« kar z nasutjem gradbenega materiala oziroma z izkopnim materialom. Vendar pa je z nasutjem ustvarimo pogoje za novo življenjsko okolje, ki večinoma traja kratko obdobje. S časom se zarastejo in spremenijo značaj goličave, kar se zgodi tudi, kadar so pozidana. Vsa ta kratkost bivanja je ob poselitvi nasutja vzeta v zakup, zato so rastline in živali svoje življenjske cikluse prilagodile takšnim, le kratek čas »ugodnim« življenjskim razmeram (Geister 1999). Na začetku se pojavijo pionirske rastline, večinoma pleveli, s časom pa se razrastejo še ostale vrste.

Z intenzivnostjo posegov v vrtače se spreminjajo tudi okoljski učinki. Z zasipavanjem vrtač se ni povečala samo nevarnost kemičnega obremenjevanja okolja, trajno se je spremenila naravna reliefna oblika in prostor katerega sestavina je. Razlogi za tako intenzivno degradacijo so $\mathrm{v}$ več desetletnem neurejenem ravnanju $\mathrm{z}$ odpadki in predvsem še danes prisotnem neodgovornem odnosu prebivalcev do narave. Vzrok je tudi v neustrezni in pomanjkljivi zakonodaji, ki bi ščitila prostor kot neobnovljiv naravni vir. 


\section{ZAŠČITA VRTAČ}

Obstoječe možnosti varovanja vrtač so omejene v glavnem na območja izven intenzivnih urbanih in agrarnih pritiskov, medtem ko je potrebno tudi vrtače znotraj in na obrobju razvijajočih se naselij zaščititi pred aktualnimi fizičnimi posegi akterjev. Zaščita vrtač mora zato temeljiti na strokovnem ovrednotenju in celostni zaščiti posamezne oblike. V primeru kraške reliefne oblike je potrebno usmeriti pozornost $v$ določanje nekaterih značilnosti krasa, kot je recimo model kraških procesov, v kraške oblike primerne za izobraževalne namene, $v$ paleogeomorfološke primere ali z vidika ekološke podpore (ohranjanje habitatov) itd (Panizza 2003).

\section{I Vrtača: naravna vrednota}

V Sloveniji so izjemne vrtače zaščitene večinoma kot naravna, lahko pa tudi kot kulturna vrednota (ledenice). Če se vsebina naravne vrednote nanaša na kulturno krajino ali spomenike oblikovane narave, varovane na podlagi zakona, ki ureja varstvo kulturne dediščine, se varstvene in razvojne usmeritve naravnih vrednot določijo v soglasju z ministrom, pristojnim za kulturno dediščino (Uradni list RS 96/2004).

Kot najpogostejši primer zaščite bomo predstavili zaščito vrtače kot naravne vrednote. Določanje in zaščito naravnih vrednot določa Zakon o ohranjanju narave (Uradni list RS 22/2003). Naravna vrednota je redek, dragocen ali znamenit naravni pojav, pa tudi sestavina žive ali nežive narave, naravno območje, ekosistem, krajina ali oblikovana narava. Naravne vrednote so zlasti geološki pojavi, minerali in fosili ter njihova nahajališča, površinski in podzemski kraški pojavi, podzemne jame, soteske in tesni ter drugi geomorfološki pojavi, ledeniki in oblike ledeniškega delovanja, izviri, slapovi, brzice, jezera, barja, potoki in reke z obrežji, morska obala, rastlinske in živalske vrste, njihovi izjemni osebki ter njihovi življenjski prostori, ekosistemi, krajina in oblikovana narava (Uradni list RS 96/2004).

Strokovna merila vrednotenja naravnih vrednot so: izjemnost, tipičnost, kompleksna povezanost, ohranjenost, redkost ter ekosistemska, znanstveno raziskovalna ali pričevalna pomembnost. Naravne vrednote obsegajo vso naravno dediščino na območju Republike Slovenije. Evidenca naravnih vrednot se gradi in izpopolnjuje od leta 1920 do danes in vsebuje 6519 enot. Od teh je 2092 državnega, 4427 pa lokalnega pomena (ARSO 2007). Varstveni režim za posamezno naravno vrednoto se vzpostavi s posebej izdelanimi pravnimi dokumenti (uredba, odlok, zakon) na državni ali lokalni (občinski) ravni. Naravne vrednote državnega pomena imajo mednarodni ali izjemen narodni pomen. Ta se ugotavlja na podlagi strokovnih meril vrednotenja primerjalno za celo državo. Na tak način so zaščitene večje, klimatsko, geomorfološko in botanično zanimive udornice v okolici Logatca, na Trnovskem gozdu, Snežniku itd in izjemne vrtače.

Na podlagi geološke karte Republike Slovenije smo izločili območja kamnin, v katerih najpogosteje nastanejo vrtače. To so apnenci, dolomiti in ostale karbonatne kamnine (breča, konglomerat, prod...). Kot je razvidno (Slika 4), je na območju Slovenije približno 53 vrtač zaščitenih kot naravna vrednota. Zakon o ohranjanju narave opredeljuje tudi posebna zava- 
rovana območja, ki lahko vključujejo tudi vrtače, ki niso posebej določene kot naravna vrednota. Posegi v te vrtače so omejeni v skladu $\mathrm{z}$ varstvenim režimom zavarovanega območja. Poznamo dve vrsti zavarovanih območij: širša zavarovana območja (narodni park, regijski park, krajinski park) in ožja zavarovana območja (strogi naravni rezervat, naravni rezervat, naravni spomenik). Na okrog $9000 \mathrm{~km}^{2}$ potencialnih območij vrtač je približno $1300 \mathrm{~km}^{2}$ površin zavarovanih kot zavarovano območje. Števila vrtač, ki so zaščitene v okviru zavarovanih območij v tej raziskavi nismo določali, ker bi bilo potrebo najprej izdelati evidenco vrtač v Sloveniji.

V nadaljevanju želimo določiti celostno ohranjanje vrtač, tako na že zaščitenih območjih vrtač na kakor tudi na nezaščitenih površinah. V okviru vsakega antropogenega posega posebej je treba strokovno opredeliti pomen prostora za ohranitev vrtač oziroma za prevlado drugih interesov.

Slika 4: Le 53 vrtač v Sloveniji je zaščitenih kot naravna vrednota.

Picture 4: Only the 53 of dolines in Slovenia are protected as a natural heritage.

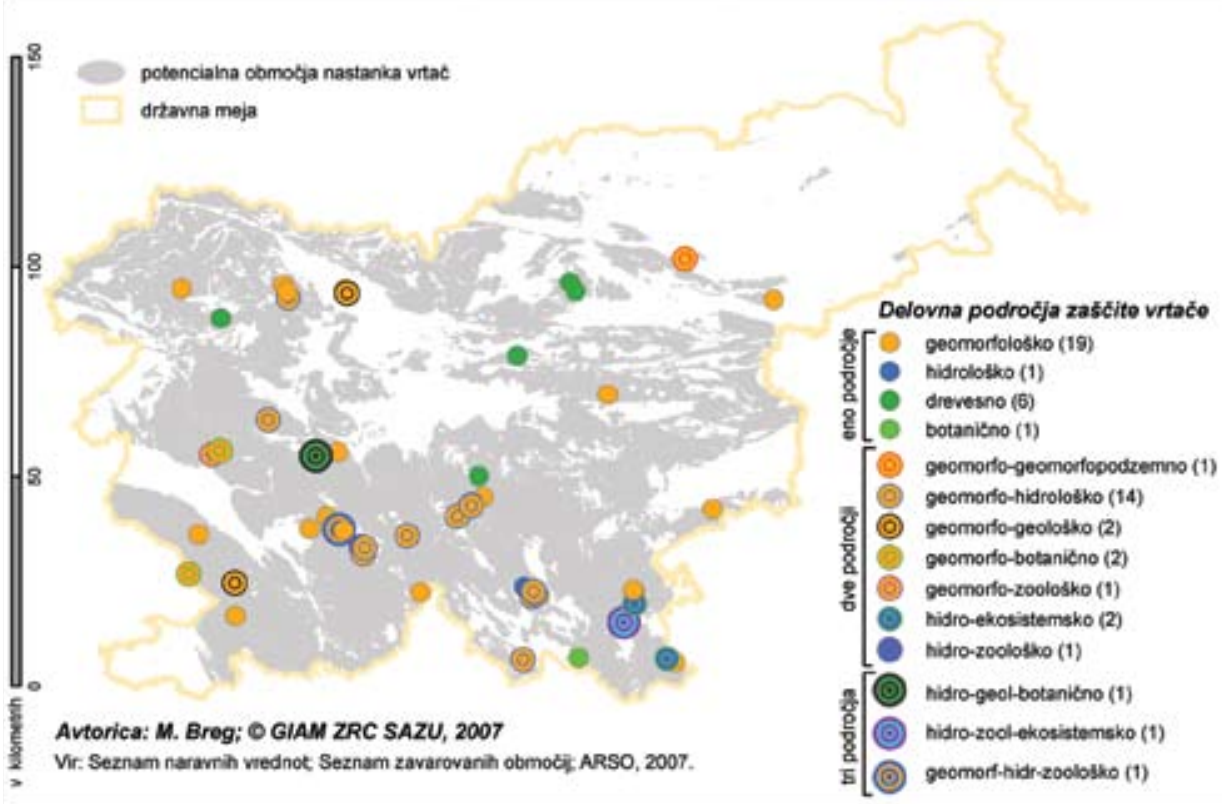

\subsection{Izhodišča za celostno vrednotenje ter trajno ohranjanje vrtač}

Temeljni zakon na področju varstva okolja je Zakon o varstvu okolja (Uradni list RS, št. 41/2004), ki pri posegih v prostor in okolje predvideva predhodno vrednotenje vplivov na okolje. Pred začetkom izvajanja posega, ki lahko pomembno vpliva na okolje, je treba izvesti presojo njegovih vplivov na okolje in pridobiti okoljevarstveno soglasje ministrstva 
in okoljevarstveno potrdilo. V postopku presoje vplivov na okolje se ugotovi, opiše in oceni dolgoročne, kratkoročne, posredne ali neposredne vplive nameravanega posega na človeka, tla, vodo, zrak, biotsko raznovrstnost in naravne vrednote (Uradni list RS, št. 41/2004). Zakon omogoča, da strokovnjaki, ki opravljajo presojo vplivov na okolje, izpostavijo tudi pomen trajnega ohranjanja določenih vrtač. Problem zakona je, da je izdelava presoj dodeljena samo določenim okoljskim strokam, ki nimajo celostnega pogleda nad pokrajinskimi sestavinami in zato poseg obravnavajo preveč ozko (npr. samo kemično onesnaženje, vpliv na habitate itd.) pri čemer sam prostor in reliefna oblika nista obravnavana kot neobnovljiv naravni vir.

Izhodišča za celostno vrednotenje vrtač najdemo tudi v Strategiji prostorskega razvoja Republike Slovenije (SPRS), katera pri načrtovanju prostorskega razvoja vključuje nekatere pomembne okoljevarstvene smernice:

- V kraških krajinah notranje Slovenije se upošteva strukturo kraških polj in podolij, druge posebnosti krasa ter ranljivost kraških vodonosnikov in podtalja (SPRS 2004, 57)."1

- $\quad$ Velika poseganja v območja z naravnimi kakovostmi morajo biti preudarna, tako da se zagotavlja nemoteno odvijanje naravnih procesov in preprečuje fragmentacijo naravnih ekosistemov ter izgubo vitalnih delov naravovarstveno pomembnih habitatov (SPRS 2004, 58). «

Reliefne oblike in fizičnogeografske procese neke pokrajine je potrebno dojemati kot pomembne pokrajinske sestavine. Alternativa je zaščita vrtače celostno z vidika prostora, ki ga zaseda vrtača, kot geomorfološka prostorska vrednota oziroma geomorfološka lokaliteta (geomorphosite) (Panizza 2003). Reliefna oblika kot lokaliteta ni vezana samo na obliko kot tako, kot pri vrednoti, ampak tudi na lokacijo, torej prostor, ki ga pokriva in na procese, ki jo oblikujejo. Reliefna oblika je, podobno kot prostor ki ga zaseda, neobnovljiv naravni vir.

$Z$ vidika fizične geografije pa vrtača ni samo geomorfološka lokaliteta. Ker pokriva geološko izjemen prostor z značilno tektonsko in razpoklinsko poroznostjo je tudi geološka lokaliteta, prav tako je zaradi značilnega pretakanja hidrološka lokaliteta. V njenem dnu se razvijejo specifične prsti in naravno rastje, prav tako na pobočju, zato je lahko tudi pedološka ali ekosistemska lokaliteta. Z vidika mikroklime v mrazišču je klimatska lokaliteta. $Z$ vidika celostne zaščite in fizične geografije jo je najprimernejše poimenovati geografska lokaliteta. Ob vseh teh izjemnostih vrtače pa prihaja do navzkrižnih interesov rabe predvsem in samo zaradi prostora, ki ga vrtača pokriva.

V nadaljevanju je predstavljen primer metodologije za celostno vrednotenje vrtače kot geografske lokalitete. Celostno vrednost vrtače strokovno določimo z upoštevanjem vloge vrtače in prostora, ki ga pokriva v neki pokrajinski enoti (Matarsko podolje, Logaško polje itd.). Metodologijo vrednotenja smo povzeli po vrednotenju geomorfoloških lokalitet, kot jo je zasnoval Panizza (2003) in jo priredili za vrtačo. Celostna vrednost vrtače je opredeljena z znanstveno vrednostjo (Q) vrtače kot tipične kraške geografske lokalitete. Vrednost določimo iz kombinacije parametrov, od katerih so nekateri v tesni povezavi z znanstvenim pomenom lokalitete, medtem ko so drugi povezani z njeno uporabo, izgledom in kulturno vlogo. Parametri se določajo za območje pokrajinskeekološke enote, kjer se pojavljajo vrtače 
(npr. Logaško polje, Matarsko podolje, Belokranjski ravnik). Določili smo osem parametrov, katerih vrednosti ustrezno ponderiramo glede na položaj in pomen vrtače v preučevanem območju:

- znanstvenoraziskovalna vrednost (Z) določena s fizičnogeografskega vidika (geomorfološka, geološka, hidrogeografska, pedogeografska, ekosistemska, mikroklimatska...);

- izobraževalna vrednost vrtače (I) za različne stopnje in oblike izobraževanja (osnovna šola, srednja šola, univerzitetni študij, podiplomski študij, učiteljski seminarji);

- $\quad$ stopnja obstoječe degradacije vrtač (D), glede na število že zasutih (pogosta odlagališča) in pozidanih vrtač na preučevanem območju, ob upoštevanju naravnih in antropogenih dejavnikov degradacije;

- obstoječa stopnja že zaščitenih vrtač (S) na preučevanem območju;

- $\quad$ pomen ozemlja $(\mathrm{O}), \mathrm{v}$ povezavi z celotnim ozemljem vrtač prisotnih na preučevanem območju (npr. Matarskem podolju);

- $\quad$ redkost (R) v povezavi s številom vrtač prisotnih na preučevanem območju;

- vizualni vtis vrtače $(\mathrm{V})$;

- Dodana vrednost (X), povezana s pomembnostjo ne-fizičnogeografskega vidika vrtače, in katera v vsakem primeru izboljša njeno znanstveno vrednost (npr. kulturni, zgodovinski, arheološki, verski vidik itd.).

Celostna vrednost vrtače se izračuna po enačbi: $\mathrm{Q}=\mathrm{zZ}+\mathrm{iI}+\mathrm{dD}+\mathrm{sS}+\mathrm{oO}+\mathrm{rR}+\mathrm{vV}+$ $\mathrm{xX}$, kjer so z, i, d, s, o, r, v, x, individualne uteži parametrov. Uteži morajo biti določene za vsako območje posebej. Skupna normalizirana Q vrednost znaša teoretično od 0 do 1.

Predlagani način vrednotenja vrtač zahteva zelo veliko raziskovalnega dela, ki je vezano prvenstveno na evidentiranje števila vrtač znotraj že zavarovanih in nezavarovanih območij, določanje njihovih parametrov, že obstoječih okoljskih pritiskov itd. Vrednotenje je treba izvesti v vseh pokrajinskih enotah, za katere so značilne vrtače, prvenstveno pa na najbolj ranljivih območjih, kjer je stopnja antropogeno degradiranih vrtač že zelo visoka. Določena morajo biti tudi območja vrtač, ki se jih dovoli zasuti in uporabiti v druge namene.

Ko je določeno območje, kjer se predvidevajo posegi v prostor, strokovno raziskano tudi z vidika pojava vrtač, je potrebno rezultate raziskave javno predstaviti domačinom in s tem postopoma oblikovati njihovo zavest o tem delčku njihove narave in okolja. »Dokler je določena reka ali posamezna reliefna oblika raziskovana in poznana samo s strani znanstvenikov in raziskovalcev, ostaja njihovo "zasebno" znanje in njen potencial kot vir se ne realizira. Ko pa znanstveniki in raziskovalci objavijo ugotovitve o reliefni obliki, razširijo vednost o njenem kulturnem in okoljskem pomenu splošni javnosti, ji s tem dodajo socialno komponento in tako reliefna oblika postane geomorfološki vir v očeh širše javnosti (Panizza 2003).« Vsekakor bo število vrtač, ki jih bomo uspeli ohraniti na nekem ozemlju, odvisno od tega, kdaj bomo uvedli zaščito in kako bomo k temu pritegnili domačine, medije in preostalo strokovno javnost. Pomembno je, da strokovnjaki razpolagamo z ustreznimi strokovnimi podlagami in podatki, ki jih lahko posredujemo tistim, ki načrtujejo in sprejemajo odločitve in s tem aktivno sodelujemo pri oblikovanju končnih odločitev. 


\section{SKLEPI}

V Sloveniji obstoječa zakonodaja ne ščiti vsake vrtače, ki je izpostavljena aktualnim urbanim in agrarnim pritiskom. Zakon o varstvu okolja sicer zahteva izdelavo presoje vplivov na okolje za posamezne posege v naravno okolje, a s tem vrtača ni celostno zaščitena pred degradacijo. Predlagani način zaščite vrtač upošteva tako prostor, kakor reliefno obliko kot naravni vir. Predvideva predhodno strokovno ovrednotenje območja vrtač z različnih vidikov in predstavitev rezultatov javnosti. Če želimo v pokrajinah, kjer so prisotne vrtače, to reliefno obliko ohraniti, kot eno izmed razpoznavnih sestavin kraške pokrajine, bo potrebno opredeliti območja vrtač, ki se morajo ohraniti že zaradi samega ohranjanja specifične kraške oblike. Določena morajo biti tudi območja vrtač, ki se jih dovoli zasuti in uporabiti v druge namene.

Gradnjo stanovanjskih sosesk na območju vrtač je treba podrejati naravnim pogojem. Prednost takšne gradnje je majhna gostota pozidave v primerjavi $\mathrm{z} »$ nevrtačastim « reliefom. Primer gradnje stanovanjskega naselja na območju večje koncentracije vrtač je Martinj hrib v Logatcu. Rodovitna prst v dnu vrtač je neobnovljiv naravni vir in še danes omogoča uporabo za ohišnice. Vrtače so se ohranile delno, večina jih je seveda spremenilo naravno obliko v kultivirano, pa vendarle niso zasute, pozidane in trajno degradirane kakor v primeru Obrtno industrijske cone Logatec (Slika 3). V takšnih primerih bi bilo potrebno ohraniti nepozidano vsaj kakšno vrtačo, ki bi jo ogradili in označili, kot naravni otok znotraj pozidanih površin in bi bila dokaz o nekdanji naravni pokrajini.

»Sodobni urbani človek«, ki se je s svojimi vsakodnevnimi dejavnostmi oddaljil od svoje domače pokrajine, se ne zaveda njenih prednosti, kakor se jih je zavedal »tradicionalni agrarni človek«. Globalizacija nam omogoča dostop do naravnih virov s celega sveta in s tem je vrednost domačih virov upadla. Pomemben vidik pri ohranjanju vrtač je zato ozaveščanje prebivalcev o značilnostih in prostorskih vrednotah domače pokrajine. Potrebno je poudarjati pomen vrtače kot naravne reliefne oblike, pomen krasotvornih procesov, ekosistemski in hidrološki pomen vrtač in vsekakor njihovo nespregledljivo vlogo v kulturni pokrajini. Prav kulturne vrtače, ki imajo stoleten stik s človekom in ležijo v bližini naselij, so bile v nedavni preteklosti kakor danes najbolj ogrožene. Hkrati pa so se nekatere ohranile in pomenijo največji potencial za sonaravne dejavnosti, kot je na primer ekološko kmetijstvo.

\section{Viri in literatura}

Breg, M. 2007a: Degradation of dolines on Logaško polje. Acta Carsologica 36. Ljubljana. Breg, M. 2007b: Spremembe rabe tal v vrtačah: primer Logatca. Raba tal. Ljubljana. (v tisku).

Digitalni ortofoto načrt 1 : 5000 (DOF): (C) 2005 Geodetska uprava Republike Slovenije. Digitalni katastrski načrt (DKN): (C 2007 Geodetska uprava Republike Slovenije.

Franciscejski kataster, Katastrska občina Dolenji Logatec, 1823. Arhiv Republike Slovenije. Gams, I. 2004: Kras v Sloveniji v prostoru in času. Inštitut za raziskovanje krasa ZRC SAZU. Ljubljana. 
Geister, I. 1999: Izbrana življenjska okolja rastlin in živali v Sloveniji. Modrijan.

Mihevc, A. 2005: Suhi zidovi in delane vrtače - antropogena preoblikovanost kraškega površja na območju Račič, Divače in Volčjega Gradu. Voda in življenje v kamniti pokrajini. Ljubljana.

Panizza, M. 2003: Karst Landforms as Geomorphosites - Kraške oblike kot geomorfološke naravne vrednote. Dela 20. Fizična geografija pred novimi izzivi. Oddelek za geografijo Filozofske fakultete Univerze v Ljubljani. Ljubljana.

Seznam naravnih vrednot, Seznam zavarovanih območij, Seznam varstvenih območji vodnih virov. 2007. Agencija Republike Slovenije za okolje. Medmrežje 1: http://kremen.arso. gov.si/NVatlas/ewmap.asp? (22.8.2007).

Smrekar, A.., Fridl, J., Kladnik, D., Breg, M. 2005: Vrednotenje nedovoljenih odlagališč odpadkov glede na nujnost njihove sanacije. Geografski vestnik 77. Ljubljana.

Strategija prostorskega razvoja Slovenije, 2004.Ljubljana.

Šebenik, I. 1994: Pokrajinske značilnosti manjših neurejenih odlagališč odpadkov v Sloveniji. Geographica Slovenica 26. Inštitut za geografijo Univerze v Ljubljani. Ljubljana.

Zakon o ohranjanju narave (Uradni list RS, št. 22/2003).

Zakon o varstvu okolja (Uradni list RS, št. 41/2004).

Zakon o varstvu podzemnih jam (Uradni list RS, št. 2/2004).

\section{ENVIRONMENTAL ASPECTS OF DOLINES PROTECTION IN SLOVENIA}

\section{Summary}

The negative and positive environmental impacts of traditional agrarian and modern usage of land are also shown. The environmental effects of the usage of dolines grow with the progress of technology, spreading of traffic and tertial and industrial activities. The meaning of the traditional usage of dolines was shown with the analysis of the division of the Franciscan and the current cadastral maps, which both show the influence of relief structure on the typical division. The environmental impacts of traditional activities are shown in the case of shifting rocks (Mihevc, 2005) and shaping of special dry walls. Modern impacts are shown as problems of filling the dolines with waste and covering with buildings. In only a few decades dumping places in dolines became an anthropogenic element of the landscape, which cannot be overlooked. Which environmental impacts are to take place, will be decided by the physical-geographic characteristics of the doline and by the type of "filling materials". Waste dumped in nature in bigger quantities has also positive environmental impacts in forming a new biotope for flora and fauna.

An example of long-term anthropogenic interventions in karst landscape is the area of Logaško polje, where the processes of degradations of dolines in the last fifty years were very intensive. It is necessary to prevent further filling of dolines with waste building materials, which arise parallel to immigrations of people and the interest for new and renewed flats and commercial-industrial areas in intensively growing settlements in the karst areas, as for 
example cities of Logatec, Sežana, Divača, Kozina etc. It was the modern and uncontrolled building and filling of the dolines which lead us to start thinking about preserving the dolines.

The legislation in Slovenia doesn't mention preservation of every doline, which is exposed to some current intensive urban and agrarian pressures. The Environment Protection Act demands an estimation of influences on the environment for each single intervention in the natural environment, but that doesn't preserve the most of the dolines. The suggested methodology of preserving the dolines takes into account the relief landform and the area which covers it as a geosite and non-renewable natural resource. It suggests a scientific estimation of the doline from different perspectives and the introduction of the final results to the public. Areas of dolines and single dolines, which have to be preserved for the preservation of specific karst landform, still have to be defined in Slovenia. The suggested way of estimating the dolines demands a large amount of research work, which is primarily based on identifying the dolines within preserved and non-preserved areas and the defining of existing environmental pressures etc. The estimation has to be performed in all landscapes, where dolines are present and define the priority areas of their preservation. The mentioned methodology of valuation has to primarily be used in the most vulnerable areas, where the level of degraded dolines is the highest. The dolines, which form a hundred years old bond with mankind and are situated near the settlements, were in the recent past and are still nowadays most endangered. Those which were preserved, present the biggest potential for natural activities (ecological agriculture).

An important aspect of preserving dolines is informing the population about the characteristics of their surrounding landscape. It is important to strengthen the meaning of a doline as a natural relief landform, the meaning of karst-forming processes, the meaning of a doline in a sense of the ecosystem and hydrology and its important role in the cultural region. The amount of dolines preserved in a specific area will depend on the time of the start of the preservation processes and the way of attracting the locals, media and other scientific public. It is also important for the professionals to have the necessary suitable professional knowledge and data, which can also be mediated to those, who make plans and decisions and actively take part in making the final decisions. 